\title{
Prognostic Significance of Normal Dobutamine-Atropine Stress Sestamibi Scintigraphy in Women With Chest Pain
}

\author{
Marcel L. Geleijnse, MD, Abdou Elhendy, MD, PhD, Ron T. van Domburg, MSc, \\ Jan H. Cornel, MD, Ambroos E.M. Reijs, MSc, and Paolo M. Fioretti, MD, PhD
}

To evaluate the prognostic value of normal dobutam-
ine-atropine technetium-99m sestamibi single-photon
emission computed tomography (SPECT) perfusion im-
aging in women with chest pain and inability to
perform an adequate exercise test, 80 women with a
normal scintigram were followed up for $23 \pm 13$
months. Mean age of the patients was $61 \pm 12$ years.
Nine patients ( $11 \%$ ) had a low probability $(<10 \%)$ of
coronary artery disease, $43(54 \%)$ had an intermedi-
ate probability $(10 \%$ to $80 \%)$ of disease, and $28(35 \%)$
had a high probability ( $>80 \%$ ) of disease (including
19 patients with known coronary artery disease).
During follow-up, no major cardiac events (cardiac

7 yocardial perfusion imaging is known to improve the diagnostic accuracy of exercise electrocardiography for the detection of significant coronary artery disease, especially in patients with inadequate heart rate response ${ }^{1}$ or abnormal resting ST-T segments, ${ }^{2,3}$ and in women. ${ }^{4-6}$ In women unable to perform an adequate exercise test, dobutamine-atropine stress technetium-99m sestamibi singlephoton emission computed tomography (SPECT) perfusion imaging is a relatively new exercise-simulating stress modality. The accuracy of this technique for the detection of coronary artery disease has been examined previously ${ }^{7-12}$ and the results of these studies show that this test is useful for the assessment of the functional significance of coronary disease. Another potential use of this test, on which less information is available, is in risk stratification. Normal dobutamine stress scintigrams may identify a group of women at low risk for future cardiac events. Therefore, the purpose of the present study was to evaluate the prognostic significance of normal dobutamine stress sestamibi scintigrams in women with chest pain, in particular in relation to the pretest likelihood of coronary disease.

\section{METHODS}

Patients: We reviewed the results of all women with inability to perform an adequate exercise test,

\footnotetext{
From the Thoraxcentre and the Department of Nuclear Medicine, University Hospital Rotterdam-Dijkzigt and Erasmus University, Rotterdam, The Netherlands. Dr. Geleijnse is supported by Grant NHS 94.135 from the Dutch Heart Foundation, Rotterdam, The Netherlands, and Dr. Elhendy by the Department of Cardiology, Cairo University Hospital, Cairo, Egypt. Manuscript received September 18, 1995; revised manuscript received and accepted December $6,1995$.

Address for reprints: Paolo M. Fioretti, MD, Thoraxcentre, Ba 300, Dr Molewaterplein 40,30 15 GD Rotterdam, The Netherlands.
}

death or nonfatal myocardial infarction) occurred. One patient with known coronary disease underwent coronary bypass surgery after 3 months, and 1 patient with a $91 \%$ pretest likelihood of coronary disease underwent coronary angioplasty after 7 months. Thus, the overall incidence of (soft) cardiac events during the follow-up period was 2 of 80 patients, or $1.3 \%$ / year. It is concluded that normal dobutamine-atropine technetium-99m sestamibi SPECT perfusion imaging in women with chest pain implies an excellent prognosis, even in women with high pretest likelihood of coronary disease.

(Am J Cardiol 1996;77:1057-1061)

who underwent dobutamine-atropine stress sestamibi SPECT imaging for the evaluation of chest pain between November 1990 and January 1995 at our institution. After exclusion of patients with clinically significant valvular heart disease, congenital heart disease, previous heart transplantation, primary myocardial disease, and recent ( $<3$ months ) angioplasty, 82 patients were identified with normal scintigraphic images. Two patients with normal scintigrams, referred for the functional evaluation of known coronary artery disease before elective revascularization were also excluded. In these patients revascularization took place within 2 weeks of stress testing. The remaining 80 women constituted the final study group. Twenty-five patients had submaximal normal exercise (perfusion) studies in the past, the other 55 patients were considered to be unable to perform an adequate exercise test, mainly because of obstructive airway disease, claudication, cerebrovascular accident, or arthrosis.

Dobutamine stress test: After routine preparation, a resting electrocardiogram was recorded, intravenous access was secured, and dobutamine was administrated intravenously by an infusion pump. The infusion rate was $10 \mu \mathrm{g} / \mathrm{kg} / \mathrm{min}$ for 3 minutes, increasing by $10 \mu \mathrm{g} / \mathrm{kg} / \mathrm{min}$ every 3 minutes, up to a maximum of $40 \mu \mathrm{g} / \mathrm{kg} / \mathrm{min}$. In patients not achieving $85 \%$ of their maximal heart rate and without symptoms or signs of myocardial ischemia, atropine was administered on top of the maximal dose of dobutamine, starting with $0.25 \mathrm{mg}$ intravenously, and repeated up to a maximum of $1.0 \mathrm{mg}$ within 4 minutes with continuation of dobutamine infusion . Throughout dobutamine infusion, the electrocardiogram ( 3 leads) was continuously monitored and recorded (12 leads) at 1-minute intervals. The level of ST-segment shift was calculated, after signal aver- 
aging, by a computer-assisted system (Cardiovit CSG/12; Schiller, Baar, Switzerland). Blood pressure was measured and recorded by sphygmomanometry every 3 minutes. Reasons for interruption of the test were: horizontal or downsloping STsegment depression $>0.2 \mathrm{mV} 80 \mathrm{~ms}$ after the J point compared with baseline; ST-segment elevation $>0.1$ $\mathrm{mV}$ in patients without previous myocardial infarction; severe angina; a symptomatic reduction in systolic blood pressure $>40 \mathrm{~mm} \mathrm{Hg}$ from baseline; hypertension (blood pressure $>240 / 120 \mathrm{~mm} \mathrm{Hg}$ ); significant cardiac tachyarrhythmias; and any serious adverse effect regarded as being due to dobutamine. Metoprolol was available and used to reverse the effects of dobutamine if they did not revert spontaneously and quickly.

Perfusion imaging: At peak stress, $370 \mathrm{MBq}$ of technetium-99m sestamibi was injected intravenously, whereas dobutamine infusion was continued for at least 1 minute. Stress scintigraphic images were acquired, on average, 1 hour after the termination of the dobutamine infusion. For resting studies, patients were reinjected with $370 \mathrm{MBq}$ of technetium- $99 \mathrm{~m}$ sestamibi $\geq 24$ hours after the stress study. Image acquisition was done with a Siemens Gammasonics single-head Roter camera (Orbiter, Siemens Corp, Iselin, New Jersey). For each study, 6 oblique (short-axis) slices were defined from the apex to the base, and 3 sagittal (vertical long-axis) slices from the septum to the lateral wall. To compare the stress and rest studies, each of the 6 shortaxis slices was divided into 8 equal segments. The septal part of the 2 basal slices ( 4 segments) was not evaluated, because this region corresponds to the fibrous portion of the interventricular septum and normally exhibits reduced uptake. The apical region was assessed from the 3 central sagittal cross sections. A total of 47 segments per patient were analyzed. All patients had a normal scan, judged from the combination of visual assessment and circumferential profile analysis.

Pretest likelihood of coronary artery disease: The pretest likelihood of coronary artery disease was calculated on the basis of age, sex, and chest pain characteristics using tables published by Diamond and Forrester. ${ }^{13}$ Patients were considered to have typical angina if they complained of substernal discomfort that was precipitated by physical exertion and relieved with rest or nitroglycerin within 10 minutes. They were considered to have atypical angina if their discomfort was either not substernal, not precipitated by exertion, or not relieved by rest or nitroglycerin. If $\geq 2$ of these characteristics were absent, patients were considered to have nonanginal chest pain. Subsequently, patients were divided into those with low pretest $(<10 \%)$, intermediate pretest $(10 \%$ to $80 \%$ ), and high pretest ( $>80 \%$ ) probabilities of disease. Patients with known coronary artery disease (by myocardial infarction or coronary angiography), and thus a pretest probability of $100 \%$, were included in the latter probability group.
Follow-up: Follow-up data were obtained by outpatient clinic assessment or contacting the patient, general practitioner, and other hospitals when necessary. Outcome events were cardiac death, nonfatal myocardial infarction, coronary artery bypass surgery (CABG) and percutaneous transluminal coronary angioplasty (PTCA).

Statistical analysis: Values were expressed as mean $\pm \mathrm{SD}$, unless specified. Comparison of variables was performed with the Student's $t$ test for continuous variables and chi-square test for discrete variables. Differences at $p<0.05$ were considered significant.

\section{RESULTS}

Patient characteristics: The historical and clinical data in the study patients are listed in Table I. The mean age of the 80 women was $61 \pm 12$ years (range 39 to 81$), 10(13 \%)$ had a history of myocardial infarction, and $12(15 \%)$ had a history of revascularization. At the time of stress testing, 22 patients ( $28 \%$ ) were being treated with $\beta$ blockers, 24 (30\%) with nitrates, and $30(38 \%)$ with calcium antagonists. Fifteen patients (19\%) had typical angina, 35 (44\%) had atypical angina, and $30(38 \%)$ had nonanginal chest pain.

Dobutamine-atropine stress results: Atropine was added to dobutamine in 21 patients $(26 \%)$. Heart rate increased from $73 \pm 13$ to $133 \pm 14$ beats $/ \mathrm{min}$ at peak stress, systolic blood pressure from $151 \pm$ 23 to $158 \pm 33 \mathrm{~mm} \mathrm{Hg}$, and the double (rate-systolic blood pressure) product from $11,015 \pm 2,834$ to $21,036 \pm 4,780$ beats $\cdot \mathrm{mm} \mathrm{Hg} / \mathrm{min}$. Target heart rate $(85 \%$ of maximal) was not reached in 6 tests $(8 \%)$ because of interruption caused by angina in 2 , hypertension in 1 , symptomatic hypotension in 2 , and nausea in 1 patient. Typical angina was induced in 14 patients $(18 \%)$ and ischemic ST-segment changes were present in 8 patients $(10 \%)$. Except for the patient with severe nausea, adverse effects were unusual and minor.

Clinical outcome: The mean follow-up period was $23 \pm 13$ months (range 6 to 56 , with 64 patients still at risk at 1 year, 28 at 2 years, and 17 at 3 years).

\begin{tabular}{|lc|}
\hline TABLE I Historical and Clinical Data of the 80 Study Patients \\
\hline Historical and Clinical Characteristics & Patients (\%) \\
\hline Age (mean \pm SD) & $61 \pm 12$ \\
Risk factors & $10(13)$ \\
Diabetes & $17(21)$ \\
Hypercholesterolemia & $42(53)$ \\
Hypertension & $11(14)$ \\
Smoking & \\
History & $10(13)$ \\
Myocardial infarction & $12(15)$ \\
Revascularization & \\
Chest pain type & $15(19)$ \\
Typical & $35(44)$ \\
Arypical & $30(38)$ \\
Nonanginal & $22(28)$ \\
Medication used & $24(30)$ \\
Beta blocker & $30(38)$ \\
Nitrules & \\
Calcium antagonists & \\
\hline
\end{tabular}




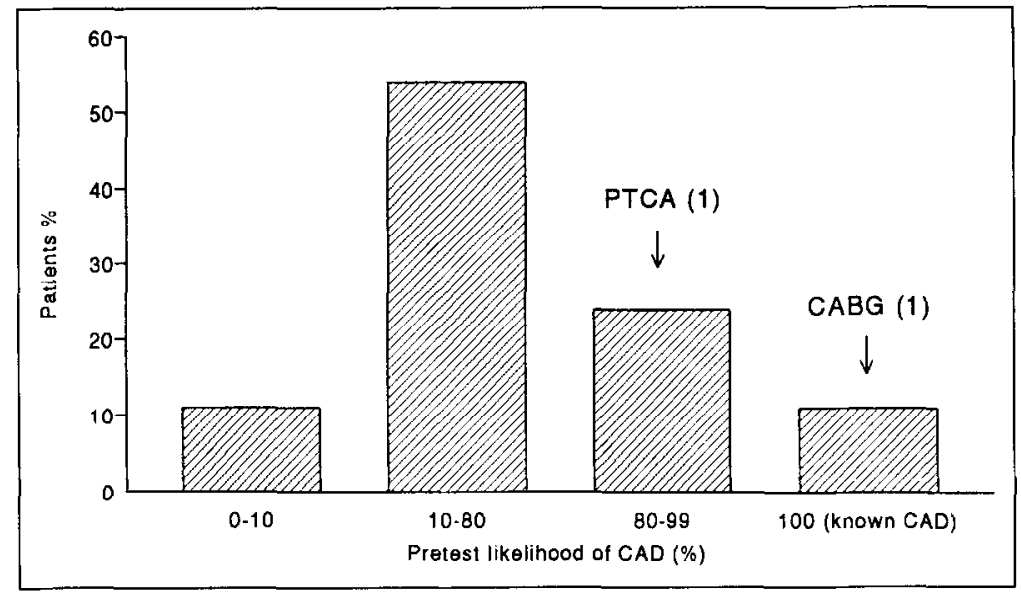

FIGURE 1. Histogram showing the distribution of events according to the pretest likelihood of coronary artery disease (CAD) in 80 study patients with chest pain and normal dobutamine-atropine sestamibi scintigram. CABG = coronary artery bypass graft; PTCA = perculaneous transluminal coronary angioplasty.

typical angina underwent repeat CABG after 3 months because of progressive angina. In this patient, the dobutamine study was interrupted at the $20 \mu \mathrm{g} / \mathrm{kg} / \mathrm{min}$ stage because of hypertension $(280 / 120 \mathrm{~mm} \mathrm{Hg})$. Heart rate at this stage was equivalent to $70 \%$ of the maximal heart rate. The second patient was a 65 -year-old woman with suspected coronary artery disease, peripheral vascular disease and multiple risk factors for coronary disease (diabetes, hypertension, smoking) presenting with typical effort angina (pretest probability of disease $>90 \%$ ). During dobutamine stress, $89 \%$ of the maximal heart rate was reached and the electrocardiogram showed minor ST elevation in the inferior leads without clinical symptoms of ischemia. The

No patient was lost to follow-up. Follow-up was "incomplete" in 5 patients because of noncardiac death after 4 (pneumonia), 8 (cancer), 18 (pneumonia), 22 (myelodysplasia), and 49 (complicated hip fracture) months of follow-up. These patients had, respectively, a $100 \%, 18 \%, 91 \%, 100 \%$ and $25 \%$ pretest likelihood of coronary artery disease. During the follow-up period, no patient suffered cardiac death or nonfatal myocardial infarction. One patient underwent CABG and another PTCA. Therefore, the annual event rate for all cardiac events was $1.3 \%$. Four additional patients with suspected coronary artery disease underwent coronary angiography. Two of these patients had normal coronary arteries, 1 had 1-vessel disease, and 1 patient had a bridging left anterior descending artery without fixed stenoses.

Cardiac events and pretest likelihood of coronary artery disease: As seen in Figure 1, nine patients (11\%) had a low probability, $43(54 \%)$ had an intermediate probability, and $28(35 \%)$ had a high probability of disease (including 19 patients with known coronary artery disease) (Figure 1). Both cardiac events occurred in patients with a high pretest likelihood of coronary disease. One 72-year-old woman with prior $\mathrm{CABG}$ (and consequently having a pretest probability of coronary disease of $100 \%$ ) presenting with scintigram was difficult to interpret because of superimposed abdominal visceral tracer activity on the inferior wall of the left ventricle, potentially responsible for a false-negative study. Subsequent coronary angiography after 7 months revealed a $>70 \%$ diameter stenoses of the midright coronary artery, which occluded acutely during the procedure. PTCA was performed in the same session.

\section{DISCUSSION}

Dobutamine is an $\alpha_{1}, \beta_{1}$, and $\beta_{2}$ receptor agonist and creates, in the presence of significant coronary stenoses, blood flow heterogeneity in a way analogous to exercise stress. ${ }^{14.15}$ Used in conjunction with sestamibi SPECT imaging, it is a relatively new stress modality, which seems to gain increasing in terest over the last years. The diagnostic usefulness of the test has been documented by other investigators $^{7-12}$ (Table II). These data show that the test is accurate, with a sensitivity of $84 \%$ (95\% confidence interval 80 to 88$)-79 \%$ for 1-vessel disease and $88 \%$ for multivessel disease-and a specificity of $71 \%$ (95\% confidence interval 67 to 76 ). However, data in these studies are mainly based on males (75\% of the patients) and, to our knowledge, there are no data available about the clinical significance of nor-

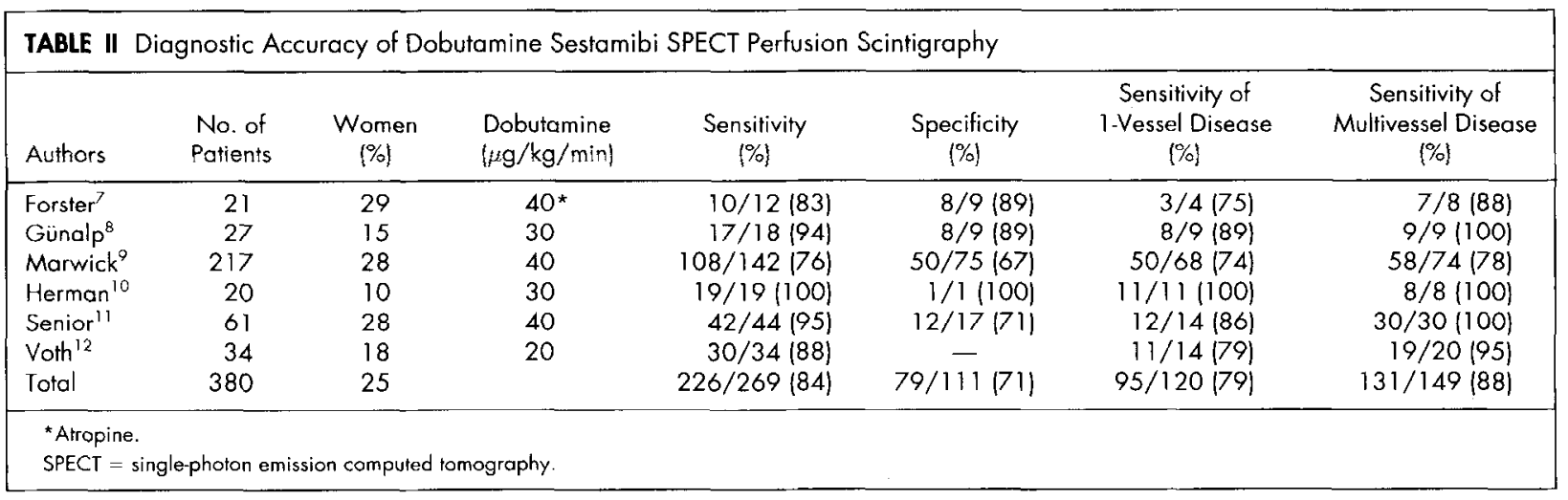


mal dobutamine sestamibi studies in women, with a stable chest pain syndrome.

Factors decreasing the sensitivity (and probably negative predictive prognostic value) of perfusion imaging in women include overestimation of breast attenuation artifacts, ${ }^{5,16}$ (misclassification of a perfusion defect as a breast attenuation artifact) and, compared with men when matched for age, lower exercise tolerance (and achieved heart rate) and increased prevalence of milder coronary disease. ${ }^{17}$ Studies on the diagnostic accuracy of exercise thallium-201 in women reported fairly low overall sensitivity of $71 \%$ to $79 \%,{ }^{4-6}$ with particularly disappointing results in detecting 1-vessel disease (sensitivity $52 \%$ to $57 \%$ ). ${ }^{4-6}$ Potential strengths of dobutamine sestamibi imaging include the exercise independency of the test and the less frequent and less severe breast attenuation artifacts compared with thallium-201 imaging. ${ }^{18}$

Our results indicate that the prognosis of women with chest pain and normal dobutamine-atropine sestamibi SPECT imaging is excellent. Cardiac events were rare, and major cardiac events, such as cardiac death and nonfatal myocardial infarction, were absent. Revascularization procedures were performed in only 2 patients, resulting in an overall annual cardiac event rate of $1.3 \%$. In 1 of these patients, the test was nondiagnostic, since only $70 \%$ of the maximal heart rate was reached. The other study represents a false-negative study in case of 1 -vessel disease, a situation in which perfusion imaging has been found to be least sensitive. ${ }^{19}$ Abdominal visceral tracer uptake was probably responsible for the normal inferior wall imaging. With the knowledge of the history of this patient and the electrocardiographic changes during dobutamine stress, it seems unlikely that this stenosis was not functionally significant at the time of the stress test.

Importantly, all cardiac events occured in patients with a high pretest likelihood of coronary artery disease. The 52 patients $(65 \%)$ with low and intermediate pretest likelihoods of coronary disease $(<80 \%)$ were free of events. This is in agreement with Bayes' theorem, that the clinical relevance of a negative test is related to the prevalence of disease in the patients studied. However, even in the subset of the 28 patients ( $35 \%$ ) with a high pretest probability of disease $(>80 \%)$, the overall annual event rate was still low (4\%), and none of these patients had a major cardiac event. These observations agree well with exercise thallium-201 reports ${ }^{20-26}$ in which (in mainly male populations) overall yearly major cardiac event rates of $<1 \%$ were reported. This low, hard cardiac event rate is comparable to that reported for patients with chest pain and angiographic normal coronary arteries. ${ }^{27,28}$

Study limitations: Two patients underwent dobutamine stress imaging after diagnostic catheterization for the evaluation of functional significance of the stenoses and underwent revascularization shortly after the stress test. Since it was already decided that they should undergo this repeated procedure, they were excluded from the follow-up study. Obviously, the main limitations of this study are the few patients $(\mathrm{n}=80)$ and the relatively short follow-up (mean 23 months). Future studies are needed in larger cohorts of women with extended follow-up to confirm our results and to clearify the long-term prognosis.

Clinical implications: Many of the women with chest pain studied by dobutamine-atropine stress technetium-99m SPECT perfusion imaging may have a normal stress scintigram. This can be puzzling, particularly in women with typical angina and/ or a high pretest likelihood of coronary artery disease. However, this study shows that both patients with low or intermediate probability and those with a high probability of disease have an excellent cardiac prognosis.

1. Iskandrian AS, Heo J, Kong B, Lyons E. Effect of exercise level on the ability of thallium-201 tomographic imaging in detecting coronary artery disease: analysis of 461 patients. $J$ Am Coll Cardiol $1989 ; 14: 1477-1486$

2. McCarthy DM, Blood DK, Sciacca RR, Cannon PJ. Single dose myocardial perfusion imaging with thallium-201; application in patients with nondiagnustic electrocardiographic stress test. Am J Cardiol 1979;43:899-906.

3. Iskandrian AS, Wasserman LA, Anderson GS, Hakki AH, Segal BL, Kane SA. Merits of stress thallium-201 myocardial perfusion imaging in patients with inconclusive exercise electrocardiograms: correlation with coronary arteriograms. Am J Cardiol 1980;46:553-558.

4. Friedman TD, Greene AC, Iskandrian AS, Hakki AH, Kane SA, Segal BL. Exercise thallium-201 myocardial scintigraphy in women: correlation with coronary angiography. Am J Cardiol 1982;49:1632-1637.

5. Chae SC, Heo J, Iskandrian AS, Wasserleben V, Cave V. Identification of extensive coronary artery disease in women by exercise single-photon emission computed tomographic (SPECT) thallium imaging. J Am Coll Cardiol $1993 ; 21: 1305-1311$.

6. Hung J, Chaitman BR, Lam J, Lesperance J, Dupras G, Fines P, Bourassa MG. Noninvasive diagnostic test choices for the evaluation of coronary artery disease in women: a multivariate comparison of cardiac fluoroscopy, exercise electrocardiography and exercise thallium myocardial perfusion scintigraphy. $J$ Am Coll Cardiol 1984;4:8-16.

7. Forster T, McNeill AJ, Salustri A, Reijs AE, El-Said ES, Roelandt JRTC Fioretti PM. Simultaneous dobutamine stress echocardiography and $99 \mathrm{~m}$ technetium isonitrile single photon emission computed tomography in patients with suspected coronary artery disease. $J$ Am Coll Cardiol $1993 ; 21: 1591-1596$.

8. Günalp B, Dokumaci B, Uyan C, Vardareli E, Isik E, Bayhan H, Özgüven M, Öztürk E. Value of dobutamine Technetium-99m-Sestamibi SPECT and echocardiography in the detection of coronary artery disease compared with coronary angiography. $J$ Nucl Med 1993;34:889-894.

9. Marwick T, D'Hondt A, Baudhuin T, Willemart B, Wijns W, Detry JM, Melin J. Optimal use of dobutamine stress for the detection and evaluation of coronary artcry disease: combination with echocardiography or scintigraphy, or both? J Am Coll Cardiol 1993;22:159-167.

10. Herman SD, Labresh KA, Santos-Ocampo CD, Ewing Garber C, Barbour MM, Messinger DE, Cloutier DJ, Ahlberg AW, Heller GV. Comparison of dobutamine and exercise using technetium-99m sestamibi imaging for the evaluation of coronary artery disease, Am J Cardiol 1994;73:164-169.

11. Senior R, Sridhara BS, Anagnostou E, Handler C, Raftery EB, Lahiri A Synergistic value of simultaneous stress dobutamine sestamibi single-photon emission computerized tomography in the detection of coronary artery disease. Am Heart J 1994;128:713-718.

12. Voth E, Baer FM, Theissen $P$, Schneider CA, Sechtem U, Schicha $H$. Dobutamine $99 \mathrm{~m}$-Tc-MIBI single-photon emission tomography: non-exercise-de pendent detection of haemodynamically significant coronary artery stenoses. Eur I Nucl Med 1904;21:537-544.

13. Diamond GA, Forrester JS. Analysis of probability as an aid in the clinical diagnosis of coronary artery disease. $N$ Engl J Med 1979;300:1350-1358.

14. Fung AY, Gallagher KP, Buda AJ. The physiologic basis of dobutamine as compared with dipyridamole stress interventions in the assessment of critical coronary stenosis. Circulation 1987;76:943-951

15. Meyer SL, Curry GC, Donsey MS, Twieg DB, Parkey RW, Willerson JT Influence of dobutamine on hemodynamics and coronary blood flow in patients with and without coronary artery disease. Am J Cardiol 1976;38:103-108.

16. Gordon DePuey G, Garcia EV. Optimal specificity of thallium-201 SPECT through recognition of imaging artifacts. $J$ Nucl Med 1989;30:441-449.

17. Chaitman BR, Bourassa MG, Davis K, Rogers WJ, Tyras DH, Berger $\mathbf{R}$, Kennedy JW, Fisher L, Judkins MP, Mock MB, Killip T. Angiographic prev- 
alence of high risk coronary artery disease in patients subsets (CASS). Circulation 1981;64:360-367.

18. Garcia EV, Van Train K, Maddahi J, Prigent F, Friedman J, Areeda J, Waxman A, Berman DS. Quantification of rotational thallium-201 myocardial tomography. J Nucl Med 1985;26:17-26.

19. Iskandrian AS, Haaz W, Segal BL. Exercise thallium-201 imaging: clinical implications of normal exercise images. Arch Intern Med $1981 ; 141: 501-503$

20. Wahl JM, Hakki AH, Iskandrian AS. Prognostic implications of normal exercise thallium-201 images. Arch Intern Med 1985;145:253-256.

21. Pamelia FX, Gibson RS, Watson DD, Craddock GB, Sirowatka J, Beller GA. Prognosis with chest pain and normal thallium-201 exercise scintigrams. Am J Cardiol 1985:55:920-926

22. Wackers FJT, Russo DJ, Russo D, Clements JP. Prognostic siginificance of normal quantitative planar thallium-201 stress scintigraphy in patients with chest pain. J Am Coll Cardiol 1985;6:27-30.

23. Heo J, Thompson WO, Iskandrian AS. Prognostic implications of normal exercise thallium images. Am $J$ Noninvas Cardiol 1987;1:209-212.
24. Brown KA, Rowen M. Prognstic value of a normal exercise myocardial perfusion imaging study in patients with angiographically significant coronary artery disease. Am J Cardiol 1993;71:865-867.

25. Steinberg EH, Koss JH, Lee M, Grunwald AM, Bodenheimer MM. Prognostic significance from 10-year follow-up of a qualitatively normal planar exercise thallium test in suspected coronary attery disease. An $/$ Cardiol 1993;71:1270-1273.

26. Fattah AA, Kamal AM, Pancholy S, Ghods M, Russell J, Cassek D, Wasserleben V, Heo J, Iskandrian AS. Prognostic implications of normal exercise tomographic thallium images in patients with angiographic evidence of significant coronary artery disease. Am J Cardiol 1994;74:769-771.

27. Papanicolaou MN, Califf RM, Hlatky MA, McKinnis RA, Harrell FE Ir, Mark DB, McCants B, Rosati RA, Lee KL, Pryor DB. Prognostic implications of angiographically normal and insignificantly narrowed coronary arteries. Am $J$ Cardiol 1986;58:1181-1187.

28. Kemp HG, Kronmal RA, Vlietstra RE, Frye RL. Seven year survival of patients with normal or near normal coronary arteriograms: a CASS registry study. J Am Coll Cardiol 1986:7:479-483. 